\title{
Usability and consistency of harm information in drug product descriptions: a matched comparison of data between the United States (US) and Europe
}

\author{
Victoria R Cornelius ${ }^{1 *}$, Kun Liu', Janet Peacock' ${ }^{1}$, Odile Sauzet ${ }^{2}$ \\ From The 4th Meeting of the Core Outcome Measures in Effectiveness Trials (COMET) Initiative \\ Rome, Italy. 19-20 November 2014
}

\section{Background}

Good information on the harm of a drug is vital to inform risk-benefit decisions and undertake robust cost effectiveness analysis. Clinical trials reported in peerreviewed articles are not useful for this purpose [1,2]. Regulators require pharmaceutical companies to produce product information documents (Europe:SmPC, US:USPI). These documents contain comprehensive and valuable publicly available information on the known harm of a drug and have the potential to inform important risk-benefit decisions. We reviewed the usefulness of the data presented and compared the harm profile reported in documents for brand drugs marketed in Europe and the US.

\section{Method}

Inclusion: Antidepressants/antiepileptic brand drugs evaluated in randomised trials of neuropathic pain and marketed in the US and Europe. Documentation was obtained from the European Medicines Agency and Food Drug Agency.

\section{Results}

Twelve brand drugs with matching SmPC and USPI were included. The number of harms ranged from 56 to 265 for SmPC and 65 to 425 for USPI (Table 1). On average the USPI contained 70 more harms than the SmPC (Figure 1). Large numbers of AEs are collected during clinical trials, the criterion for selecting harms to report was seldom clear. Twelve of the 24 documents did report selection criteria but for 8 of these the criteria varied within the document. Medical terminology dictionaries are used to code AEs with an aim to standardised reports. More USPIs than SmPCs specified the dictionary used $(6 / 12 \mathrm{v} 3 / 12)$. No matched documents reported using the same dictionaries.

\section{Discussion}

It is expected that the harm profile in the product information for the same drug should agree. This study found a lack of consistency for the same drug based on the same central data available to the pharmaceutical company, and demonstrates the overwhelming impact of using arbitrary rules for reporting and differing dictionaries to code harm data. This problem can only be exacerbated across drugs.

The development of CORE harm outcome sets by drug class would improve the usability of this information by facilitating comparison of harm profiles across drug which would support informed riskbenefit decisions and allow robust cost effectiveness analyses.

\section{Authors' details \\ 'Dept Primary Care and Public Health Sciences, King's College London, London, SE1 3QD UK. ${ }^{2}$ AG Epidemiology and International Public Health, University of Bielefeld, D-33501 Bielefeld, Germany.}

Published: 29 May 2015

\footnotetext{
* Correspondence: Victoria.cornelius@kcl.ac.uk

'Dept Primary Care and Public Health Sciences, King's College London,

London, SE1 3QD UK

Full list of author information is available at the end of the article
} 
Table 1. Summary of number of harms by document

\begin{tabular}{lcccccc}
\hline & $\begin{array}{c}\text { Median \# harms reported } \\
\text { (range) }\end{array}$ & $\begin{array}{c}\text { Median \# harms reported only in one } \\
\text { document(range) }\end{array}$ & $\begin{array}{c}\text { Median \# median \# of the same harms reported by both } \\
\text { documents (range) }\end{array}$ \\
\hline SmPC & 114 & $(56,265)$ & 43 & $(20,181)$ & 75 & $(36,104)$ \\
\hline USPI & 200 & $(65,425)$ & 168 & $(38,336)$ & & \\
\hline
\end{tabular}

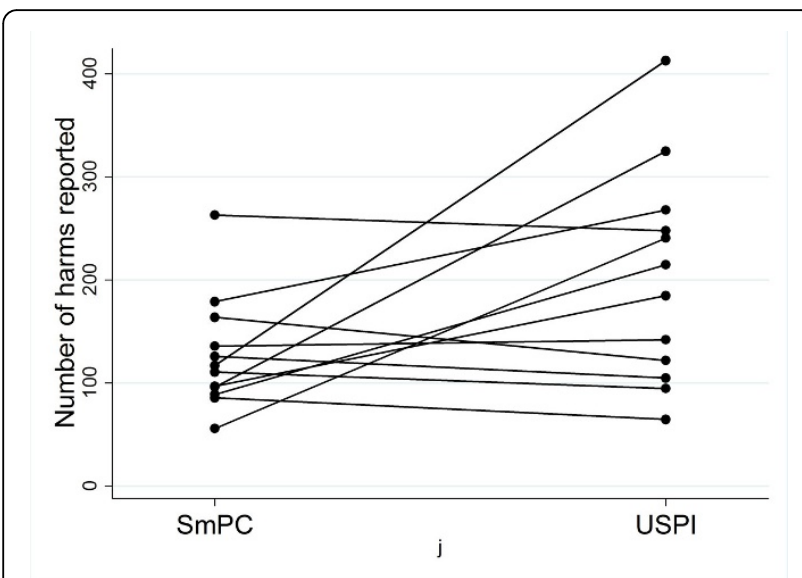

Figure 1 Number of harms reported by matched document

\section{References}

1. Cornelius VR, Sauzet O, Williams JE, et al: Adverse event reporting in randomised controlled trials of neuropathic pain: considerations for future practice. Pain 2013, 154(2):213-220.

2. Ioannidis JP: Adverse events in randomized trials: neglected, restricted, distorted, and silenced. Arch Intern Med 2009, 169(19):1737-1739.

doi:10.1186/1745-6215-16-S1-P17

Cite this article as: Cornelius et al:: Usability and consistency of harm information in drug product descriptions: a matched comparison of data between the United States (US) and Europe. Trials 2015 16(Suppl 1):P17.

Submit your next manuscript to BioMed Central and take full advantage of:

- Convenient online submission

- Thorough peer review

- No space constraints or color figure charges

- Immediate publication on acceptance

- Inclusion in PubMed, CAS, Scopus and Google Scholar

- Research which is freely available for redistribution

Submit your manuscript at www.biomedcentral.com/submit
C Biomed Central 